Ann. Biol. anim. Bioch. Biophys., 1978, 18 (2A), 305-316.

\title{
Concentration of monovalent ions in aqueous solutions : effect on the conductance of liquid lipid artificial membranes
}

par M. BARA

Laborafoire de Biologie de la Reproduction, Université P.-et-M. Curie, Bât. A

7, quai Saint-Bernard, 75230 Paris Cedex 05, France.

Summary. Varying the ionic concentration of aqueous solutions bathing a liquid artificial membrane (phospholipids dissolved in an organic solvent with a weak dielectric constant and impregnating a teflon millipore filter), lipid-ion interactions on phospholipid organization have been demonstrated inside the membranes. The conductance, $g$, has been measured. There was a close and significant correlation between the increase of $\mathrm{g}$ and the variation in ionic concentration; $g$ did not increase continuously but in sequential steps to reach a plateau at high concentrations, whatever phospholipid was used, monovalent cation studied or $\mathrm{pH}$ chosen. This sequential step increase of $\mathrm{g}$ could be explained by the following hypothesis : inside and on the surface of the membrane, polar groups organized into three different types according to the ionic concentration of aqueous solutions; if the organization remained the same, the energy environment changed under the influence of the surrounding medium.

\section{Introduction.}

Lipid-protein interactions inside living or artificial membranes are physiologically important, but lipid-ion interactions are liable to affect membrane structure and permeability. Tobias ef al. (1962), Mikulecky and Tobias (1964) and Bara (1976) using liquid lipid artificial membranes, Papahadjopoulos (1968) monolayers and Ohki (1972) black lipid membranes, reported that mono or bivalent cations bathing both sides of a membrane change the potential, resistance and perhaps structural organization of these membranes.

This paper reports the influence of the ionic concentration of an aqueous solution on lipid reorganization inside the membrane. The change in liquid lipid artificial membrane conductance was measured while the ionic concentration of salt solutions on both sides of these membranes was experimentally modified.

\section{Material and methods.}

The phospholipid liquid artificial membranes described by Sollner $(1945 a, b, c)$ and Dean (1947) were made following the method of Bara (1976). These membranes were chosen in preference to solid macroscopic artificial membranes because they favourably react within an anhydrous medium of weak dielectric constant in which 
ion-site interactions are very specific. The phospholipids used to form the membranes, i.e. phosphatidylethanolamine (PE), phosphatidylcholine (PC), phosphatidyl-L-serine (PS), were extracted from ox brain (Mueller et al., 1963) or taken from commercialized preparations (egg lecithin, Merck ; animal cephalin, Fluka AG ; phosphatidyl-L-serine, Sigma). Identical results were obtained with all these methods.

The purity of the phospholipids was controlled by chromatography through a silicic acid-celit 545 column and by a thin-layer chromatography. The products were revealed by ninhydrin (PE, PS) and by Dragendörff reagent (PC).

The teflon millipore filter (Mitex type ; thickness : $150 \mu \mathrm{m}$; porosity : 60 p. 100 ; pore size : $5.0 \mu \mathrm{m}$ ) was essentially lipophilic and hydrophobic. This filter was impregnated by dipping in phospholipids dissolved at 0.1 or 2 p. 100 concentration in a heptan-chloroform-methanol solution (7:2:1). Experimental variation of the proportion of the charged molecules in an organic solvent, permits the study of amphiphilic molecular organization in a medium having a weak dielectric constant.

The heterogeneous filter-solvent-phospholipid system possesses a hydrophobic matrix and aqueous pores showing a high site density. Phospholipid distribution however has not been well defined (Tobias et al., 1962) ; the amount of lipids adsorbed on the filter can only be weighed (Yoshida et al., 1971). The functional structure of this model appears to be of a micellar type.

The aqueous solutions $(12 \mathrm{ml})$ were kept at $22^{\circ} \mathrm{C} \pm 10$ temperature during experimental modification of the $\mathrm{pH}$. The solution concentration bathing the membrane was increased from 0.001 to $1 \mathrm{M}$ using a peristaltic pump to add ions on both sides of the membrane. The solutions were continually stirred by teflon-coated bar magnets.

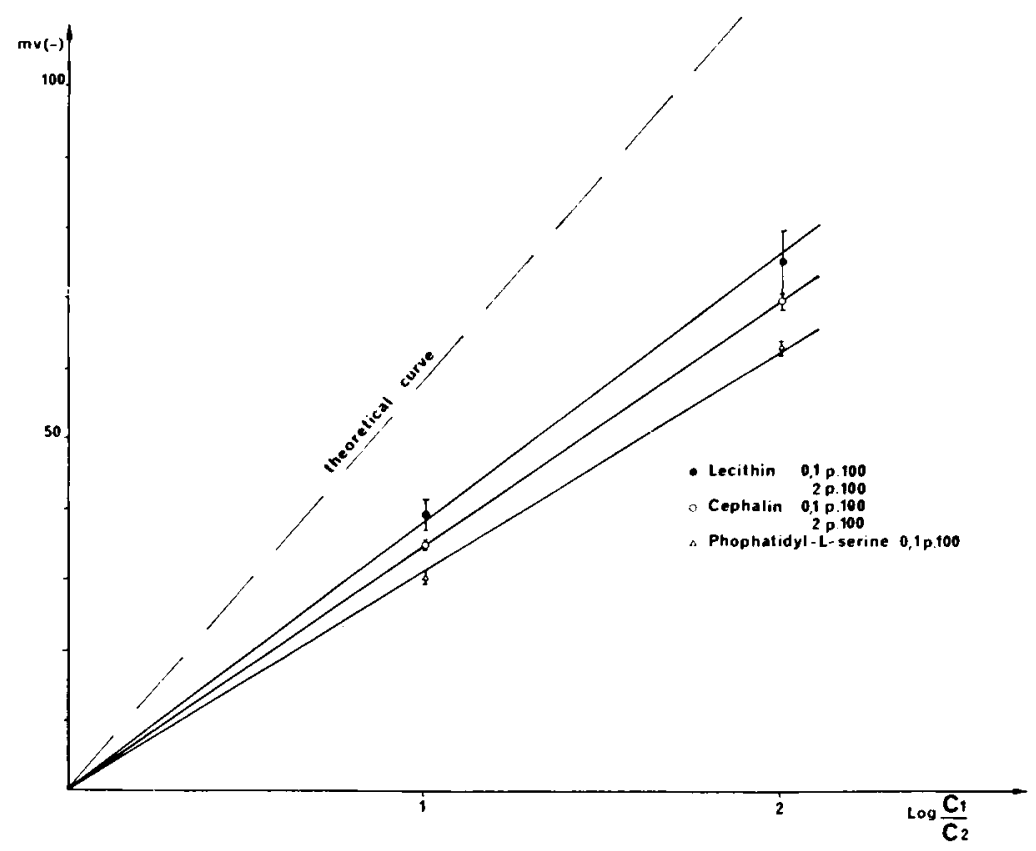

FIG. 1. - Concentration potentials

( $C_{1}$ and $C_{2}=$ ionic concentration of aqueous solutions bathing the membrane). 
The potential between the two electrodes with no membrane was subtracted from the measured potential to obtain the appropriate membrane potential $(\mathrm{Vm})$. Concentration potentials between the two electrodes were determined to define the selectivity range of the membrane towards cations or anions. Conductance measurements $\left(\mathrm{g}=1 / \mathrm{R}\right.$, mho. $\left.\mathrm{cm}^{-2}\right)$ give direct figures for ion motility in an organic phase, if the charge density remains constant; for these measurements, the membrane was submitted to constant step voltage provided by a stabilized input. The electric current flowing in the circuit was measured with an ammeter (Keithley electrometer $610 \mathrm{~B}$ ).

\section{Results.}

Concentration potentials (fig. 1).

As shown by the concentration potentials, membranes exchange cations; they do not present a perfect cationic activity. These data confirm the results published by

\section{TABLE 1}

0,1 p. 100 phospholipid concentration : conductance g evolution and levels in function of ionic concentration of aqueous solutions

Ionic concentration variation

$$
\mathrm{g}\left(10^{-7} \mathrm{mho} \cdot \mathrm{cm}^{-2}\right)
$$

g Evolution

\begin{tabular}{rrrrr} 
Lecithin from 0.001 to $0.002 \mathrm{M}$ & $0.83 \pm 0.04$ to $0.89 \pm 0.03$ & plateau \\
\hline 0.002 to $0.005 \mathrm{M}$ & $0.89 \pm 0.03$ to $7.6 \pm 0.4$ & $\begin{array}{c}\text { g increases exponentially } 8 \\
\text { to } 9 \text { times }\end{array}$ \\
\hline 0.005 to $0.01 \mathrm{M}$ & $7.6 \pm 0.4$ to $8.1 \pm 0.4$ & plateau \\
\hline 0.01 to $0.02 \mathrm{M}$ & $8.1 \pm 0.4$ to 48 & \pm 5 & $\mathrm{~g}$ increases 5 to 6 times \\
\hline 0.02 to $0.2 \mathrm{M}$ & $48 \quad \pm 5 \quad$ to 77 & \pm 3 & $\begin{array}{c}\text { g changes slower and rea- } \\
\text { ches exponentially to- } \\
\text { wards a plateau }\end{array}$
\end{tabular}

0.2 to $1 \quad M \quad 77 \pm 3$ to $81 \pm 4 \quad$ g reaches a plateau

\begin{tabular}{rrrrrrr} 
Cephalin from 0.001 to 0.01 & $M$ & $7.3 \pm 0.2$ to $8.4 \pm 0.3$ & plateau \\
\hline 0.01 to 0.02 & $M$ & $8.4 \pm 0.3$ to 65 & \pm 3 & $\begin{array}{c}\text { g increases exponentially } \\
8 \text { times }\end{array}$ \\
\hline 0.02 to 1 & $M$ & 65 & \pm 3 & to 84 & \pm 3 & $\begin{array}{c}\text { g increases slowly and } \\
\text { reaches a plateau }\end{array}$
\end{tabular}

\begin{tabular}{lrlllllll}
$\begin{array}{l}\text { Phosphatidyl } \\
\text { L-serine }\end{array}$ & from 0.001 to 0.01 & $M$ & $7.2 \pm 0.9$ & to 7.8 & \pm 0.8 & plateau \\
\hline 0.01 to 0.02 & $M$ & 7.8 & \pm 0.8 & to 34 & \pm 2 & $\begin{array}{c}9 \text { increases exponentially } \\
4 \text { to } 5 \text { times }\end{array}$ \\
\hline 0.02 to 0.1 & $M$ & 34 & \pm 2 & to 70 & \pm 3 & g doubles, linearly \\
\hline 0.1 to 1 & $M$ & 70 & \pm 3 & to 77 & \pm 4 & plateau
\end{tabular}


Shiratori et al. $(1968 a, b)$. However, it is surprising that this activity appears lower with phosphatidylserine. The range of cationic selectivity does not depend on phospholipid concentration; the graphs are identical when lecithin or cephalin are used at $0.1 \mathrm{gram}$ or $2 \mathrm{gram}$ dilution in the solvent.

\section{Conductance.}

Membrane conductance changes in a similar way, whatever the monovalent cation ( $\mathrm{Li}, \mathrm{K}, \mathrm{Na}, \mathrm{Cs}, \mathrm{Rb}$ chlorides) and the $\mathrm{pH}$.

0.1 p. 100 phospholipid solution. - The results obtained are summarized in table 1 and figures 2 and 3 . Three main conductance levels are found for the three phospholipids :

-0.001 to $0.1 \mathrm{M}: \mathrm{g}$ varies little (lecithin excepted, as $\mathrm{g}$ increases 8 to 9 times between 0.002 and $0.005 \mathrm{M})$;

- 0.01 to $0.02 \mathrm{M}$ : the ionic concentration doubles but conductance increases 4 to 8 times according to the phospholipid studied. At $0.02 \mathrm{M}$ concentration, the conductance of the various membranes appears significantly different $(p<0.01)$, according to the following sequence : $g_{\text {ceph. }}>g_{\text {lec }}>g_{\text {pho-ser. }}$;

-0.02 to $1 \mathrm{M}: \mathrm{g}$ slowly increases until it reaches a plateau.

2 p. 100 phospholipid solution. - The results are summarized in table 2 and figures 4 and 5. There are three main conductance levels for lecithin and four levels for cephalin with a common level (between 0.005 and $0.02 \mathrm{M}$ ) when $\mathrm{g}$ increases 25 to 30 times for lecithin and 5 times for cephalin. At the lowest ionic concentration, cephalin mem-

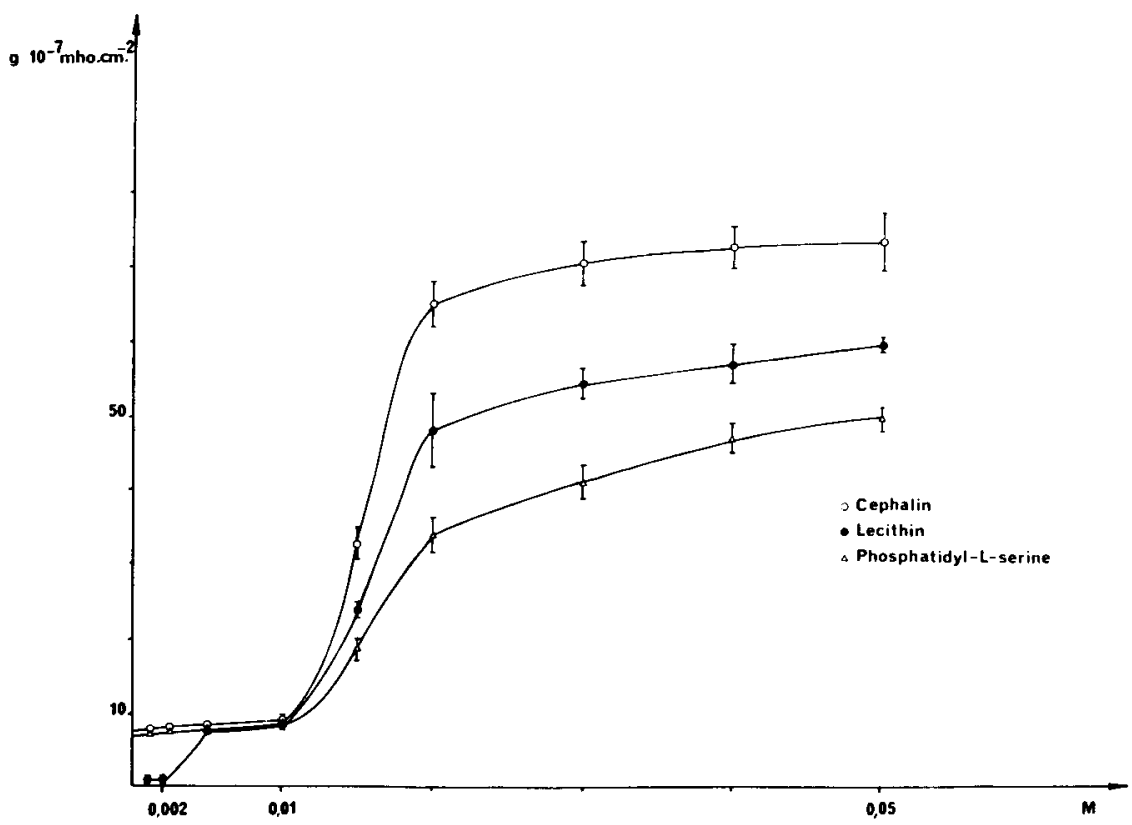

FIG. 2. - Liquid membrane conductance variation ( 0.1 p. 100 lecithin, cephalin, phosphatidyl-serine) in function of the ionic concentration of the external aqueous solutions (from 0 to $0.05 \mathrm{M}$ ). 


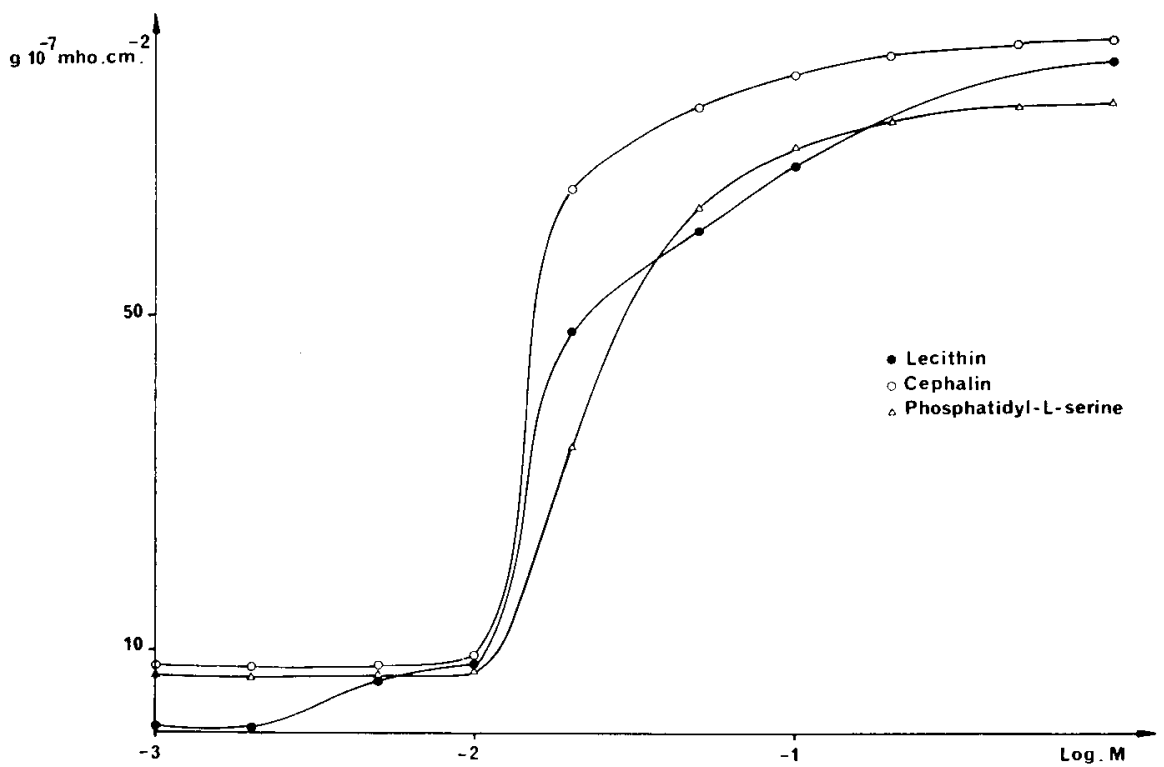

FIG. 3. - Liquid membrane conductance $g$ variation ( 0.1 p. 100 phospholipids concentration) in function of the ionic concentration logarithmic of external aqueous solutions : $g$ increases by steps.

TABLE 2

2 p. 100 phospholipid concentration : conductance $g$ evolution and levels in function of ionic concentration of aqueous solutions

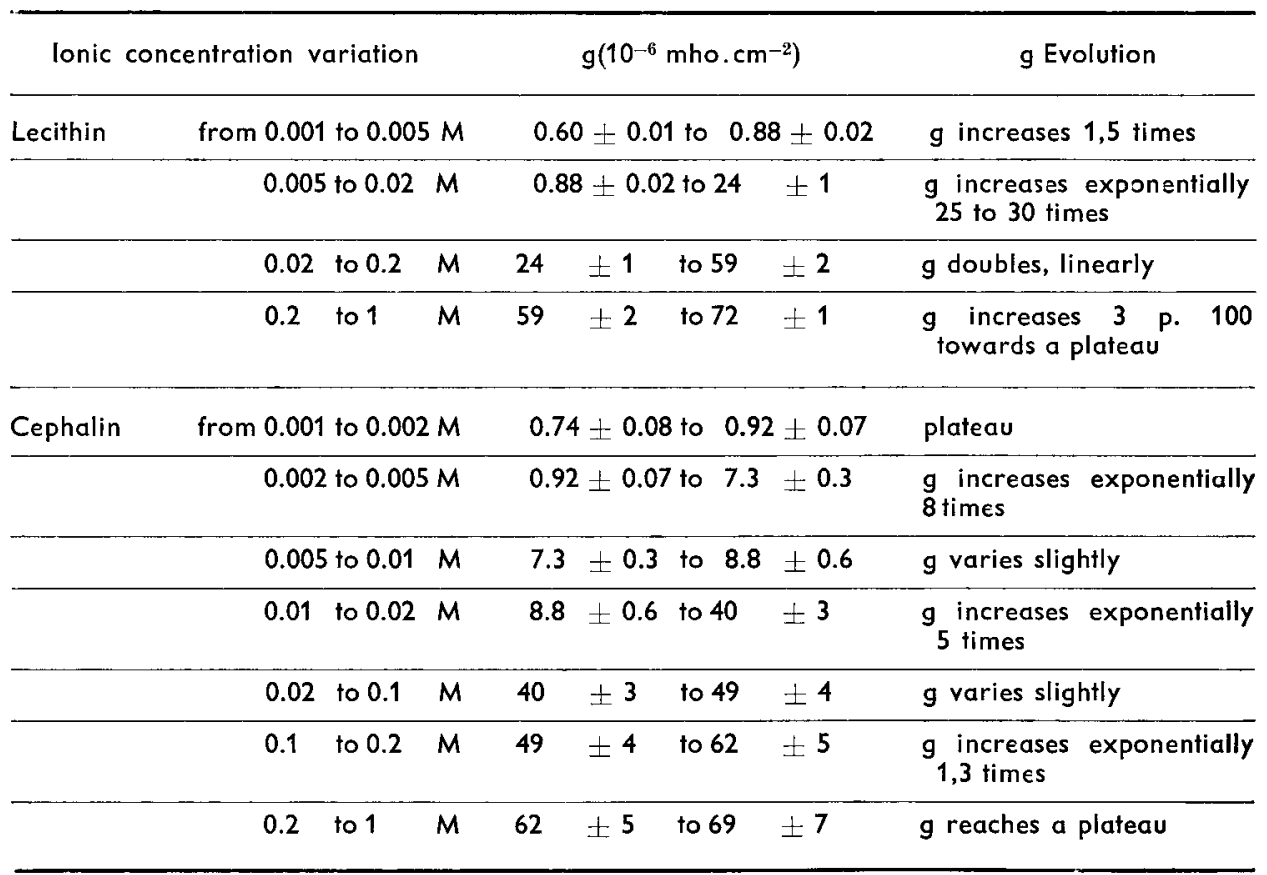




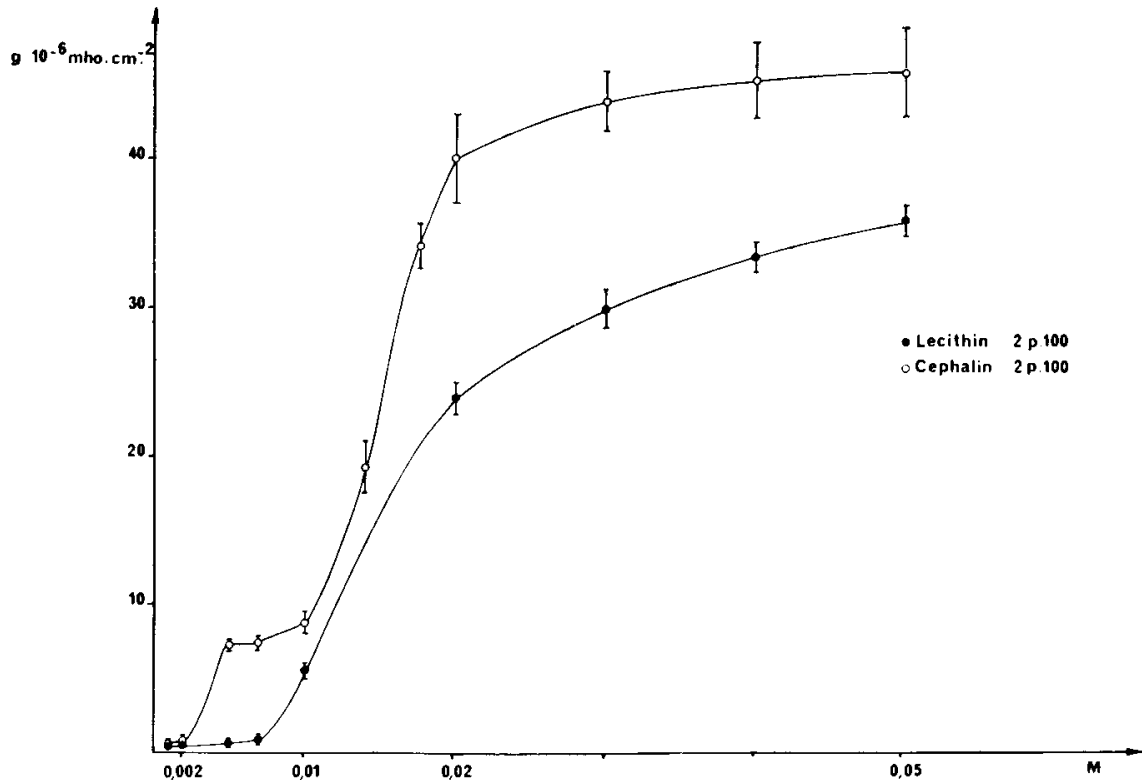

FIG. 4. - Liquid membrane conductonce $g$ variation (2 p. 100 phospholipids concentration) in function of the ionic concentration of the exfernal aqueous solutions (from 0 to $0.05 \mathrm{M}$ ).

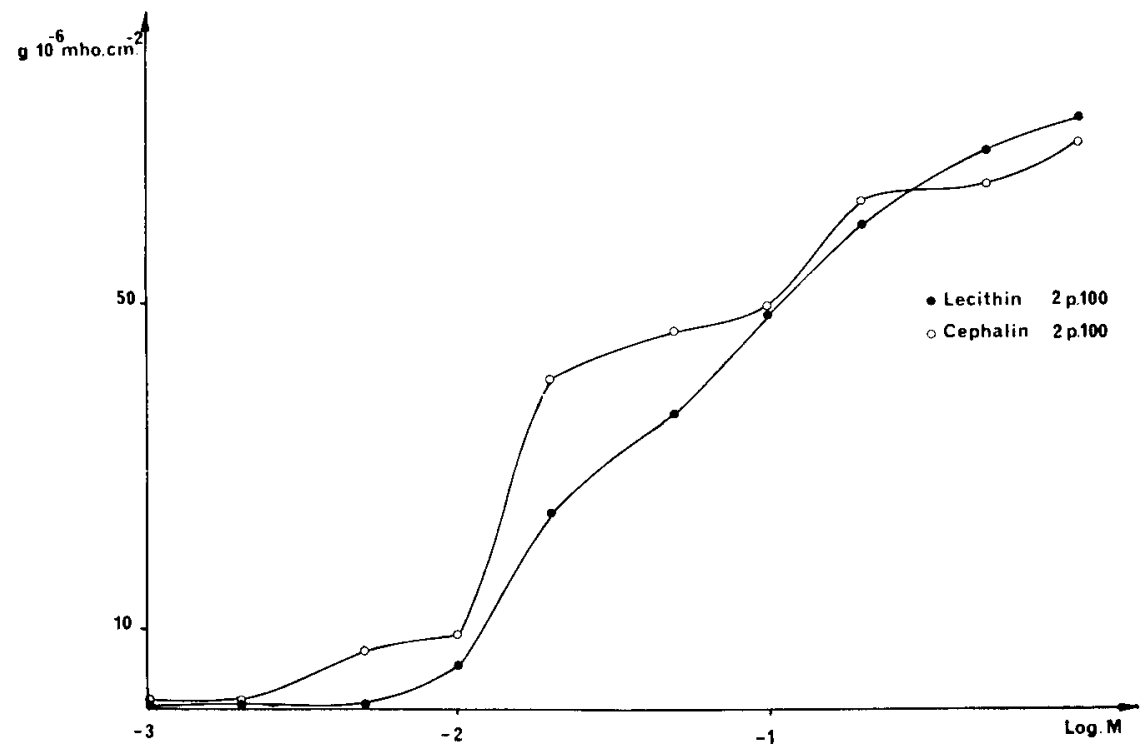

FIG. 5. - Liquid membrane conductance $g$ variation (2 p. 100 phospholipids concentration) in function of the ionic concentration logarithmic of external aqueous solutions. 
brane conductance does not significantly differ from that of lecithin membranes, but when the ionic concentration increases, $g_{c e p h}$. always remains significantly above glec.

Lecithin or cephalin membrane conductance saturation is not reached at $1 \mathrm{M}$. If $X \mathrm{Cl}$ concentration is increased up to $2 \mathrm{M}$, the conductance will again increase by sequential steps to reach a saturation curve at around $2 \mathrm{M}$ concentration.

Comparison between the two phospholipid concentrations. - For a twentyfold increase in phospholipid concentration, $g$ is multiplied by 10 . Almost identical conductance levels are found once again using the two phospholipid concentrations. It is interesting to observe that the highest conductance increase always takes place from $0.001-0.005$ to $0.02 \mathrm{M}$. In addition, the main sequence of conductance is :

$$
\text { geeph. }>g_{\text {lec. }}>g_{\text {pho-ser. }} \text {. }
$$

\section{Discussion.}

According to Parsegian (1969), the self-energy of a charge, $E$, is given by the formula :

$$
E=\frac{e^{2}}{E h c .1} \ln \frac{2 E w}{E w+E h c}
$$

$\mathrm{e}=$ charge magnitude of the ion ; Ehc = dielectric constant of the membrane ; $E w=$ dielectric constant of the aqueous phase ; I = thickness of the membrane.

An energy, $E$, equal to $40 \mathrm{Kcal} /$ mole is necessary to move a monovalent ion from an aqueous solution towards a phase which has a 2.5 dielectric constant (like heptan). In this case, the partition coefficient between the two phases reaches $10^{-15}$.

In our model, the dielectric constant was not measured, but the conductance values of phospholipid concentration in the solvent $\left(0.88 .10^{-7} \mathrm{mho} . \mathrm{cm}^{-2}\right.$ to 0.1 p. 100 ; $7.1 .10^{-7}$ mho. $\mathrm{cm}^{-2}$ to 1 p. $100 ; 54.10^{-7}$ mho. $\mathrm{cm}^{-2}$ to 2 p. 100 lecithin), suggest the existence of aqueous pores, probably due to phospholipid polar-head organization. Parsegian calculated that the energy necessary for the penetration of a monovalent ion in the aqueous phase of a $5 \AA$ radius pore amounts to $6 \mathrm{kcal} / \mathrm{mole}$. In addition, if the pore is lined with charged sites, the energy becomes weaker ; in case of a carrier system, the energy reaches 16 to $27 \mathrm{kcal} / \mathrm{mole}$.

Thus, the model we have used is an heterogeneous system showing a well marked but imperfect cationic activity (fig. 1), including an hydrophobic matrix and perhaps aqueous pores with a high site density (with 2 p. 100 phospholipids, $3 \mathrm{mM}$ of phospholipid theoretic concentration per liter of solvent is obtained). According to llani (1965), however, the charge inside a pore having a $5 \AA$ radius and $100 \AA$ length, corresponds to the site concentration of $300 \mathrm{mM}$ per liter solvent. Due to phospholipid organization, it is legitimate to expect a high site density and accordingly high hydrophilia. Interionic discrimination increases when phospholipid concentration decreases in the membrane as well as hydrophilia (Yoshida et al., 1972).

Mikulecky and Tobias (1964) using a millipore filter impregnated with cephalincholesterol, described the interaction between counterions and fixed sites in two ways : (i) by the statement of Donnan equilibrium parameters, (ii) by the description of the 
system as an equilibrium among the membrane, the counterions and the membranecounterion complex. In the first case, the membrane aqueous phase is viewed as homogeneous but different from the external aqueous phase due to the presence of the fixed charge. The interaction between membrane and counterion is purely electrostatic. In the second case, the membrane aqueous phase is identical with the external solution and cations are associated with the fixed sites which can be considered to be outside the aqueous phase. This case is not limited to electrostatic interactions alone.

For the three phospholipids studied (lecithin, cephalin, phosphatidyl-serine), there is a significant correlation between increased conductance and an augmentation in the ionic concentration of the aqueous solutions. The correlation coefficient which has been calculated reaches the following :

$\begin{array}{lcl}\text { lecithin } & 0.1 \text { p. } 100: r=0.60(p<0.02) \\ \text { cephalin } & -\quad: r=0.59(p<0.05) \\ \text { phosphatidyl-serine } & -\quad: r=0.73(p<0.02) \\ \text { lecithin } & 2 \text { p. } 100: r=0.66(p<0.025) \\ \text { cephalin } & -: r=0.72(p<0.025) .\end{array}$

The significant correlation coefficient shows that the conductance of the various membranes is closely linked to the ionic concentration of the aqueous solutions. This correlation coefficient seems to be more significant for high lipid concentration as well as for phosphatidyl-serine which shows a carboxylic group, although the comparison between correlation coefficients is not significant $(P=0.7)$. In addition, from $0.01 \mathrm{M}$, when $\mathrm{g}$ varies considerably, phosphatidyl-serine membrane conductance drops significantly lower than that of other lipid membranes $(p<0.02)$, in spite of the presence of a carboxylic group. This fact suggests the presence, at the surface and inside the membrane, of sites with an energetic environment varying with the surrounding medium. The conductance sequences can thus be explained.

The increased number of amphiphilic molecules due to the augmentation in phospholipid concentration, results in increased conductance as well as a shift of the saturation zone ( $2 \mathrm{M}$ instead of $1 \mathrm{M}$ ).

Using these data, the following hypothesis can be suggested : the interactions between ions and membranes are not exclusively electrostatic because phosphatidylserine membrane conductance is weaker and the correlation between conductance and ionic concentration of aqueous solutions is close but imperfect. This hypothesis confirms Mikulecky and Tobias'system.

For the three phospholipids which have been studied, the stronger conductance related to the increase in ionic concentration of the aqueous solutions is not a continuous phenomenon, but occurs through sequential steps whatever the phospholipid concentration in the organic solvent. This demonstrates that polar groups are structured from the beginning in the same way and that future organization depends on the surrounding ionic concentration.

Ion and lipid association is further shown by the curve representing the relation between conductance and ionic concentration of an aqueous solution which varies little with the $\mathrm{pH}$, showing that it is not due to permeation of the membrane following a proton-cation exchange. If semi-logarithmic co-ordinates are used to trace the theoretical dissociation or ionic association curve $(g=f(\log M)$, fig. 6$)$, this curve corres- 


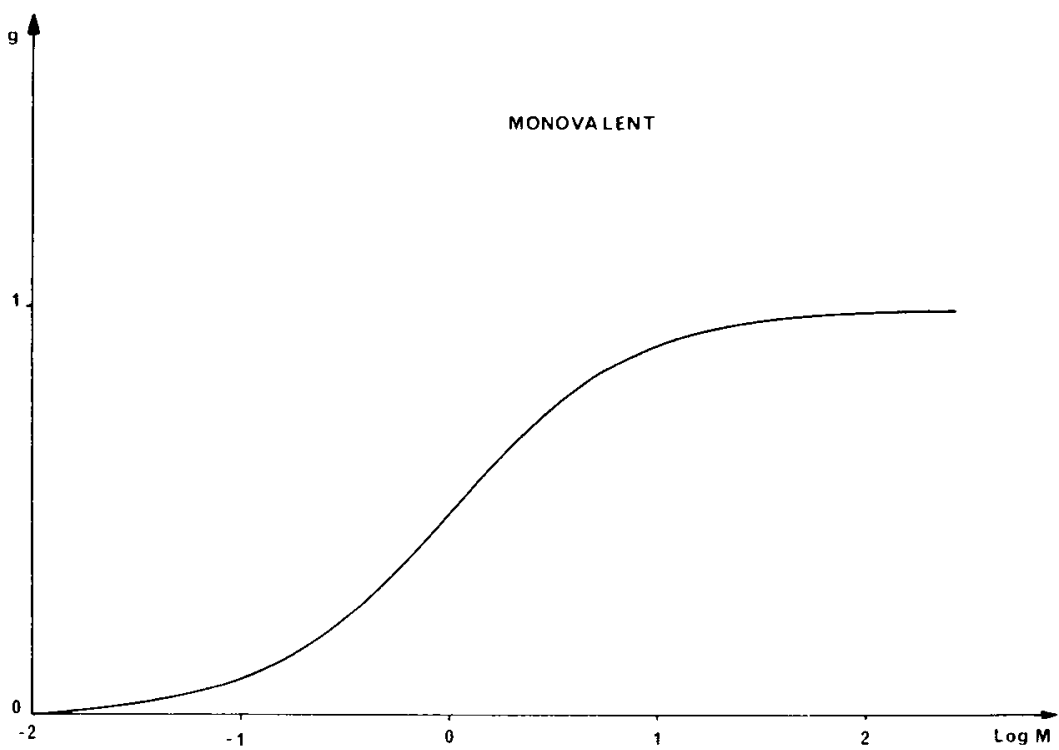

FIG. 6. - Conductance variation in function of the salt concentration logarithmic of aqueous solutions for a monovalent cation (the graph increases by steps and reaches a plateau).

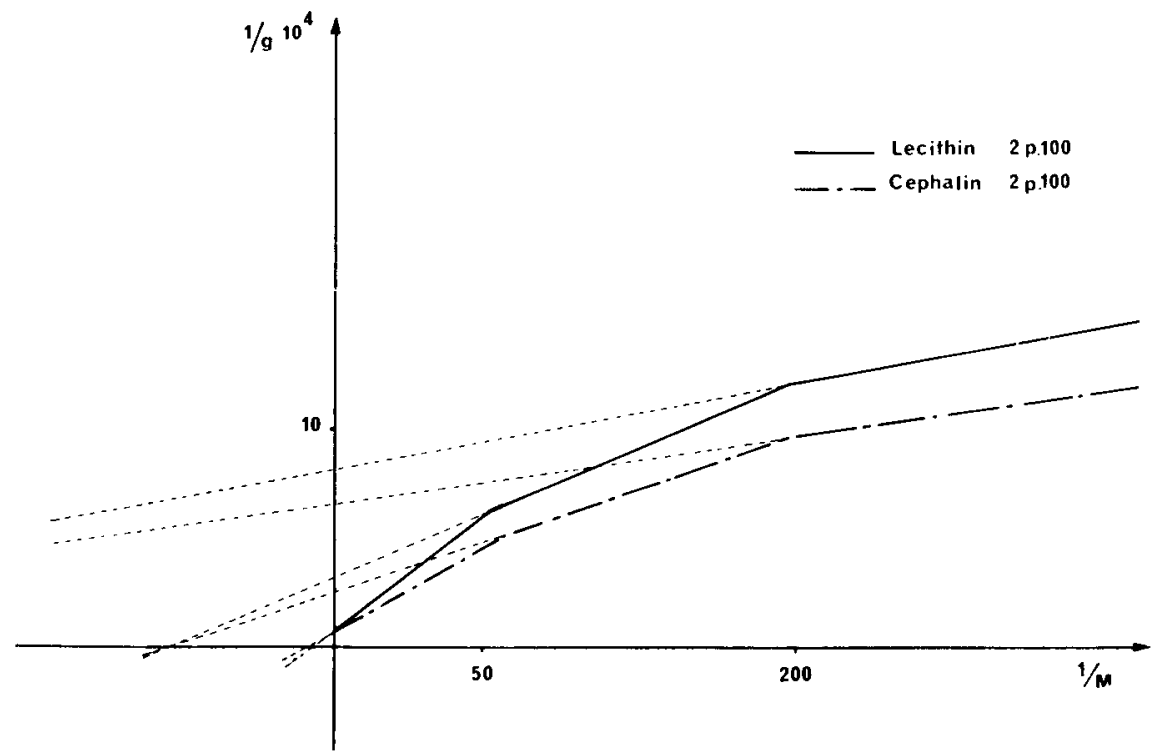

FIG. 7. $-\mathrm{I} / \mathrm{g}=\mathrm{f}(\mathrm{I} / \mathrm{M})(2$ p. 100 lecithin and cephalin concentration). Revelation of 3 apparent $\mathrm{Km}$, i.e. 3 apparent dissociation constants thus showing the presence of three site or polar group organizations in the membrane, unmasked one after the other when the ionic concentration of aqueous solutions increases. 
ponds to the experimental curves which have been obtained. This similarity demonstrates the association between the ions and the lipids of the membranes in our study.

We can also plot $1 / \mathrm{g}$ in function of $1 / \mathrm{M}$ as Nakamura and Yasumasu (1974) have done in an enzyme study using $: 1 / \mathrm{g}=1 / \mathrm{kg}_{\max }+1 / \mathrm{g}_{\max } \cdot 1 / \mathrm{M}$. With a curve representing $1 / \mathrm{g}$ in function of $1 / \mathrm{M}$ for lecithin and cephalin membranes at $2 \mathrm{p} .100$ concentration (fig. 7), the following results are obtained :

- with dilute aqueous solutions, $1 / \mathrm{km}$ is large, and the accordingly apparent $\mathrm{km}$ is small ; as a consequence, the affinity between ion and phospholipid polar groups is high. This may indicate that scattered sites are present but masked on the surface and that the conductance recorded is then mixed (this observation is also valid for 0.1 p. 100 lipid concentration);

- with more concentrated aqueous solutions, two other rather largely apparent $\mathrm{Km}$ are found, thus characterizing sites with a more reduced affinity, i.e. three categories of site or polar group reorganization are thus unmasked, one after the other, when ionic concentration of aqueous solutions increases.

Although the system studied here is not enzymatic, kinetic studies lead to the following hypothesis : there may be three types of sites inside and on the surface of the membranes we have used, i.e. three types of polar group organization, depending on the ionic concentration of aqueous solutions or of identical sites ; energetic environment changes would be due to the surrounding medium. Shohami and Ilani (1973a et $b$ ) using cellulose acetate or nitrate and bromobenzene membranes, have shown that if the membrane contains fixed charges, the electrostatic attraction between the sites and the ions could be influenced by the surrounding medium. Remembering that the conductance is both anionic and cationic and that the conductance-site relation is not univocal, several functional answers may be considered:

- If there exists a link between $\mathrm{PO}_{4}^{-}$and $\mathrm{NH}_{3}^{+}$groups (Rosano ef al., 1961), unmasking and stripping phenomena revealing some polar groups could take place, leading to the liberation of different sites and increased conductance; the cations would squeeze in between the acid and amino groups and the links with a definite external concentration would be broken, thus explaining the sudden conductance increase since this group reactivity depends on the number of ions present. Using millipore filters impregnated with cephalin-cholesterol, Tobias ef al. (1962) have shown that when the dissociation is important the cations can easily migrate from one group to another under the influence of an electromotive force. The conductance then increases if the fixed sites are used as transmembranous steps.

- Related to this mechanism there is the classical system of screening effect with charges (Kruyt, 1949) which favors cationic conductance.

- Lastly, these phenomena must be related to those observed by Dervichian (1956) : in an organic solvent, the ionized lipids scatter in micellae with the paraffin parts towards the outside and the polar groups directed towards the inside. Cations, as dyes, might be present inside the micellae in the water which bathes the polar groups because phospholipids behave as anions and fix cations. At low ionic concentration, the membrane is formed by an aggregate of micellae which contains the cations, but when ionic concentration increases, the micellae detach and $g$ then increases through sequential conductance steps. 


\section{Conclusion.}

Varying the ionic concentration of aqueous solutions has shown that monovalent ions influence the organization of phospholipids inside living and artificial membranes. According to the number of cations which are present, various sites on the surface and inside the membrane are liberated, thus increasing conductance. If the sites are identical, their energetic environment will be modified depending on the ionic medium.

The membrane model used has a complex structure and is not very clear. It has evidenced important ion-lipid interactions, but only suggests an hypothesis explaining membrane permeability.

Reçu en mars 1977.

Accepté en décembre 1977.

Résumé. En faisant varier la concentration ionique des solutions aqueuses baignant une membrane artificielle de «type liquide» (phospholipides dissous dans un solvant organique à faible constante diélectrique et imprégnant un filtre millipore en téflon), nous avons voulu mettre en évidence les interactions lipides-ions et leur action sur l'organisation des groupes polaires des phospholipides au sein des membranes. Les mesures effectuées sont des mesures de conductance $\mathrm{g}$. II existe une corrélation étroite et significative entre l'augmentation de $\mathrm{g}$ et la variation de concentration ionique ; mais l'accroissement de $\mathrm{g}$ se fait de manière non continue, par « paliers » successifs pour atteindre un plateau vers de fortes concentrations, quels que soient le phospholipide employé, le cation monovalent étudié ef le $\mathrm{pH}$ choisi. Cette augmentation de $\mathrm{g}$, par paliers successifs, peut s'expliquer par les hypothèses suivantes : il y aurait dans ef à la surface de la membrane trois organisations différentes des groupes polaires selon la concentration ionique des solutions aqueuses ou une organisation identique mais un environnement énergétique sous la dépendance du milieu ambiant.

\section{References}

BARA M., 1976. Effets du magnésium sur des membranes liquides et bimoléculaires phospholipidiques. L'ion magnésium compétiteur des cations monovalents. Ann. Biol. anim. Bioch. Biophys., 16, 121-128.

DEAN R. B., 1947. The effects produced by diffusion in aqueous systems containing membranes. Chem. Rev., 41, 503-523.

DERVICHIAN D. G., 1956. Sur la nature des liaisons possibles entre les lipides ef les protéines du sérum. 3rd inter. Conf. on biochemical problems of lipids, 26-28 July 1956. The blood lipids and the clearing factor, 21-34.

ILANI A., 1965. Ion discrimination by « millipore » filters saturated with organic solvent. II. Significance of hydrophobic medium. Bioch. bioph. Acta, 94, 415-424.

KRUYT H. R., 1949. Colloid science. I. Irreversible systems. II. Reversible sysiems. Elsevier Publ. Comp., Inc.

MIKULECKY D. C., TOBIAS J. M., 1964. Phospholipid-cholesterol membrane model. I. Correlation of resistance with ion content. J. cell. comp. Physiol., 64, 151-164.

MUELLER P., RUDIN D. O., TITIEN H., WESCOTT W. C., 1963. Methods for the formation of single bimolecular lipid membranes in aqueous solutions. J. phys. Chem., 67, 534-535.

NAKAMURA M., YASUMASU I., 1974. Mechanism for increase in intracellular concentration of free calcium fertilized sea urchin egg. J. gen. Physiol., 63, 374-383.

OHKI S., 1972. Membrane potential of phospholipid bilayers : ion concentration and $\mathrm{pH}$ difference. Bioch. bioph. Acta, 282, 55-71.

PAPAHADJOPOULOS D., 1968. Surface properties of acidic phospholipids : interaction of monolayers and hydrated crystals with uni- and bivalents ions. Bioch. bioph. Acta, 163, 240-254. 
PARSEGIAN V. A., 1969. Energy of an ion crossing a low dielectric membrane : solutions to four relevant electrostatic problems. Nature, 221, 844-846.

ROSANO H. L., SCHULMAN S. H., WEISBUCH I. B., 1961. Mechanism of the selective flux of salts and ions through non aqueous liquid membranes. Ann. N. Y. Acad. Sci, 92, 457-462.

SHIRATORI M., MIZUMO H., KOBAYASHI Y., 1968a. Studies on the transport of substances across artificial membrane reconstructed with lipids. VII. Transport of ions across lecithinmembrane. J. Tokyo Univ. Fish., 55, 53-62.

SHIRATORI M., MIZUMO H., TAGUCHI H., TAKEUCHI Y., 1968b. Studies on the transport of substances across artificial membrane reconstructed with lipids. VI. Transport of ions across cephalin-membrane. J. Tokyo Univ. Fish., 55, 45-51.

SHOHAMI E., ILANI A., 1973a. Relation between the dielectric constant of hydrophobic cation exchange membrane and membrane permeability to counterions. Bioph. J., 13, 1232-1241.

SHOHAMI E., ILANI A., 1973b. Model hydrophobic ion exhange membrane. Bioph. J., 13, 12421260.

SOLLNER K., 1945a. The physical chemistry of membranes with particular reference to the electrical behavior of membranes of porous character. I. The nature of physico-chemical membranes as physiochemical machines; preparation and properties of membranes of highly pronounced electrical properties. J. phys. Chem., 49, 47-67.

SOLLNER K., 1945b. The physical chemistry of membranes with particular reference to the electrical behavior of membranes of porous character. II. The nature of the dried collodion membrane Some current membrane theories and their limitation. J. phys. Chem., 49, 171-191.

SOLLNER K., 1945c. The physical chemistry of membranes with particular reference to the electrical behavior of membranes of porous character. III. The geometrical and electrical structure of membranes of porous character. Some examples of the machine action of membranes. $J$. phys. Chem., 49, 265-280.

TOBIAS J. M., AGIN D. P., PAWLOWSKI R., 1962. Phospholipid-cholesterol membrane model. Control of resistance by ions or current flow. J. gen. Physiol., 45, 989-1001.

YOSHIDA M., KAMO N., KOBATAKE Y., 1972. Transport phenomena in a model membrane accompanying a conformational change : membrane potential and ion permeability. $\mathrm{J}$. Memb. Biol., 8, 389-402.

YOSHIDA M., KOBATAKE Y., HASHIMOTO M., MORITA S., 1971. Studies of electric capacitance of membranes. II. Conformational change in a model membrane composed of a filter paper and a lipid analogue. J. Memb. Biol., 5, 185-199. 